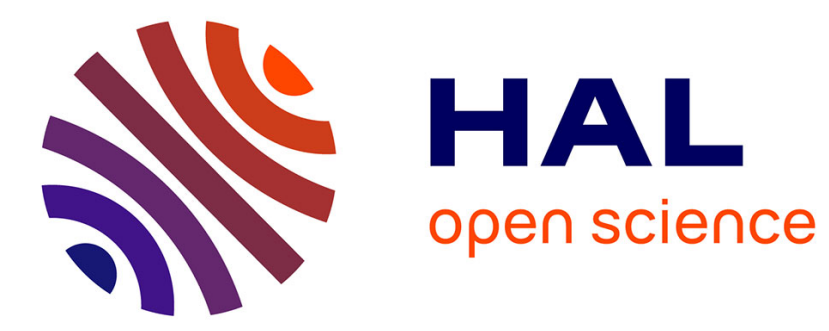

\title{
Is the severity of adolescent conduct disorder associated with the level of nicotine dependence?
}

\author{
Kaisa Riala, Essi Ilomäki, Helinä Hakko, Pirkko Räsänen
}

\section{To cite this version:}

Kaisa Riala, Essi Ilomäki, Helinä Hakko, Pirkko Räsänen. Is the severity of adolescent conduct disorder associated with the level of nicotine dependence?. European Child and Adolescent Psychiatry, 2011, 20 (8), pp.393-399. 10.1007/s00787-011-0189-x . hal-00701911

\section{HAL Id: hal-00701911 \\ https://hal.science/hal-00701911}

Submitted on 28 May 2012

HAL is a multi-disciplinary open access archive for the deposit and dissemination of scientific research documents, whether they are published or not. The documents may come from teaching and research institutions in France or abroad, or from public or private research centers.
L'archive ouverte pluridisciplinaire HAL, est destinée au dépôt et à la diffusion de documents scientifiques de niveau recherche, publiés ou non, émanant des établissements d'enseignement et de recherche français ou étrangers, des laboratoires publics ou privés. 


\section{Is the severity of adolescent conduct disorder associated with the level of nicotine dependence?}

Kaisa Riala ${ }^{2}$, M.D., Ph.D., Essi Ilomäki ${ }^{1}$, M.D., Helinä Hakko ${ }^{2}$, Ph.D., Pirkko Räsänen ${ }^{1}$, Professor, and the STUDY-70 workgroup

${ }^{1}$ University of Oulu, Department of Psychiatry, BOX 5000, 90014 University of Oulu, Finland

${ }^{2}$ Oulu University Hospital, Department of Psychiatry, BOX 26, 90029 OYS, Finland

Correspondence: Kaisa Riala

Oulu University Hospital, Department of Psychiatry

BOX 26, 90029 OYS

Finland

+358-400-569247, e-mail: kaisa.riala@oulu.fi

fax $+358-8-3157256$ 


\section{Abstract}

Objective: Our aim was to investigate the relationship between the number of Conduct Disorder (CD) symptoms and specific DSM-IV symptom subscales (i.e. aggression towards people and animals, destruction of property, deceitfulness or theft, and serious violations of rules) and nicotine dependence (ND) among adolescent psychiatric inpatients in Finland.

Methods: A total of 171 adolescents with CD (99 boys, 72 girls; age 12-17 years) were admitted to inpatient psychiatric hospitalization between April 2001 and March 2006. Information on their psychiatric DSM-IV diagnoses was obtained using the Schedule for Affective Disorder and Schizophrenia for School-Age Children (K-SADS-PL). The level of ND was assessed with the modified Fagerström Tolerance Questionnaire (mFTQ).

Results: The total number of CD symptoms correlated with the level of ND among both the boys (adj. $r=0.31, p=0.002)$ and the girls (adj. $r=0.324, p=0.006)$. For the boys the number of conduct symptoms correlated with the level of ND on all subscales except for aggression, while the only statistically significant correlation for the girls was found with the deceitfulness or theft subscale. A comorbid substance use disorder was statistically significantly associated with a high level of ND among both the boys $(\mathrm{p}<0.001)$ and the girls $(\mathrm{p}=0.019)$.

Conclusions: Our results suggest that both in adolescent boys and girls, the greater the number of CD symptoms, the higher the level of ND. Future studies are needed on the relationship between environmental factors, non-aggressive CD symptoms and the development of ND among adolescents with CD.

Author Keywords: Nicotine dependence, conduct disorder, aggression, adolescent, psychiatric disorders 


\section{INTRODUCTION}

Conduct disorder (CD), as defined in the DSM-IV, is characterized by pervasive and persistent patterns of aggressive, deceptive and destructive behaviour with childhood or adolescent onset [1]. The estimated lifetime prevalence of CD in the U.S. is $9.5 \%$ (males $12.0 \%$; females $7.1 \%$ ), with a median age-of-onset of 11.6 years [2].

The prevalence of regular smoking among adolescents with CD has been found to be as high as 48$77 \%[3,4,5]$. CD seems to be an independent risk factor for the early initiation of smoking $[3,6]$ and progression to regular daily smoking $[4,7]$ or heavy smoking [8], but there have been only a few studies of the association between adolescent nicotine dependence (ND) and CD. Hakko et al. [9] found that the likelihood of a high level of ND as compared with being a non-smoker or having a moderate level of ND was over two-fold among under-aged psychiatric inpatient adolescents with conduct/oppositional disorders. Furthermore, Elkins et al. [10], who were able to investigate prospectively certain dimensional or categorical measures of $\mathrm{CD}$ and $\mathrm{ADHD}$ in relation to subsequent initiation of smoking and the development of a DSM-IV diagnosis of ND among adolescent twin pairs, found that a diagnosis of $\mathrm{CD}$ at the age of 14 years was independently associated with an increased risk of ND (OR 4.27) by 18 years of age even after adjustment for concurrent ADHD.

The DSM IV classifies CD symptoms according to four main subscales: 1) aggression towards people and animals, 2) destruction of property, 3) deceitfulness or theft, and 4) serious violations of rules (DSM IV). As far as we know, there have been no studies to date investigating these CD subscales in relation to adolescent ND. The main goals of the current work were 1) to study whether 
the number of CD symptoms is associated with the level of ND as measured by the modified Fagerström Tolerance Questionnaire (mFTQ) [11], 2) to find out whether the type of CD (group type, solitary aggressive type vs. undifferentiated type, and childhood vs. adolescent onset type) is connected with the level of adolescent ND, 3) to investigate whether gender and psychiatric comorbidity among $\mathrm{CD}$ adolescents affects the risk of developing ND, and 4) to examine how various CD symptom subscales are associated with the level of ND.

\section{METHODS}

This work is part of the STUDY-70 project, which has been described in detail earlier [12]. The original sample consisted of 508 adolescent inpatients (208 males, 40.9\%, and 300 females, 59.1\%) aged 12-17 years (mean 15.4 years; sd 1.3) consecutively admitted to Unit 70 at Oulu University Hospital, Department of Psychiatry, between April 2001 and March 2006. The catchment area of Unit 70 covers the regions of Oulu and Lapland, so that all adolescents from this area in need of acute psychiatric hospitalization in a closed ward are initially treated here. Subjects who were over 18 years, mentally retarded, had organic brain disorders or did not give written informed consent to participation were excluded from the series, with the result that $83.7 \%$ of the eligible adolescents participated in the study. The protocol was approved by the Ethics Committee of Oulu University Hospital, Finland.

\section{Subjects with CD}

The subjects were interviewed using the Schedule for Affective Disorder and Schizophrenia for School-Age Children, Present and Lifetime (K-SADS-PL), to assess DSM-IV psychiatric diagnoses [13]. K-SADS-PL is a semi-structured interview known to be a reliable method for defining adolescent DSM-IV diagnoses $[14,15]$. The interviews were carried out by the treating physician or by trained medical students under the guidance of the treating physician. If data were missing or remained 
unreliable after interviewing the adolescent, the material was supplemented by interviewing the parents. Data were recorded on the basis of both information given by the patient and the physician's evaluation of the diagnostic interview. The psychiatric diagnoses of the adolescents were subsequently scrutinized further and were carefully validated against the DSM-IV criteria by two experienced psychiatrists.

A diagnosis of CD required meeting the threshold criteria for at least three of the 15 DSM-IV CD symptoms in the past 12 months, with at least one criterion present in the past 6 months and behaviour causing clinically significant impairment. As the purpose was to investigate pure conduct symptoms, 12 subjects with concurrent ADHD (9 males, 3 females) were excluded from the study. A total of 171 adolescents (99 males and 72 females) met the DSM-IV diagnostic criteria for CD (DSM-IV 312.81, 312.82 or 312.89) and were included in the eventual series. Their mean ages were 15.3 (sd 1.44) and 15.5 (sd 1.29) years for boys and girls respectively ( $\mathrm{t}$-test $=-0.799$, df=169, $\mathrm{p}=0.425)$.

\section{CD subtypes}

The cases of $\mathrm{CD}$ were categorized into three subtypes based on the adolescents' own reports of whether the conduct symptoms had usually occurred when they were with peers, alone or both with peers and alone, 1) group type, 2) solitary aggressive type, and 3) undifferentiated type, and into two subtypes based on the age of onset of the first CD symptoms, 1) childhood-onset type (onset of at least one criterion prior to 10 years of age), and 2) adolescent-onset type (absence of any criteria prior to 10 years of age). The $15 \mathrm{CD}$ symptoms were investigated in terms of four separate subscales as categorized in DSM-IV: 1) aggression towards people and animals (7 symptoms: initiates physical fights, bullies or threatens others, aggressive stealing, use of a weapon, physical cruelty, forced sexual activity and cruelty to animals), 2) destruction of property (2 symptoms: vandalism and fire setting), 3) deceitfulness or theft (3 symptoms: telling of lies, non-aggressive 
stealing and breaking-in), and 4) serious violations of rules (3 symptoms: truancy, frequently staying out at night and running away overnight).

\section{Measure of Nicotine Dependence}

Information on current smoking habits and the level of ND was collected by means of the 7-item modified Fagerström Tolerance Questionnaire (mFTQ) for adolescents [11], the reliability and validity of which have been demonstrated previously $[16,17]$. The items in the mFTQ assess the subject's smoking rate, frequency of inhalation, interval between waking up and the first cigarette, level of unwillingness to give up the first cigarette in the morning, difficulty of refraining from smoking in places where it is forbidden, smoking despite medical illness, and smoking more during the first 2 hours than during the rest of the day. The mFTQ sum score can range from 0 to 9 . Following Prokhorov et al. (1996), a sum score of 6 or higher was considered to represent a high level of ND in the adolescents.

\section{Comorbid psychiatric diagnoses}

In order to study the association between comorbid psychiatric diagnoses and ND, the diagnoses were categorized into three major groups: 1) affective disorders (DSM-IV 296.2-.3, 300.4, 311), 2) anxiety disorders (300.00-.02, 300.21-.23, 300.29, 300.3, 308.3, 309.81), and 3) substance-related disorders (303.9, 304.0-.6, 304.8-.9, 305.0, 305.2-.7, 305.9). Multiple diagnoses were possible.

\section{Family type}

Family type was used as a confounding variable in the statistical analysis, since it is known to be associated with both smoking and conduct problems in adolescents [18, 19]. Information on family type was obtained from the K-SADS-PL assessment and covered the adolescents' rearing 
environments before admission to hospital. Four family types were recognised for the present purpose: 1) two-parent family (biological mother and biological father), 2) single-parent family (one biological parent), 3) child welfare placement, and 4) other family type (e.g. blended family, foster family).

\section{Statistical Methods}

Statistical significances of group differences were assessed with Pearson's $\chi^{2}$ Test or Fisher's Exact Test for categorical variables and with Student's t-Test, the Analysis of Variance (ANOVA) test or the Mann-Whitney U-Test for continuous variables. Partial correlation (adjusted for age) was used to examine the associations between nicotine dependence and the $\mathrm{CD}$ subscales. A regression analysis was used to investigate the association of CD symptoms, age and psychiatric disorders (affective, anxiety and substance-related disorders) with the sum score of ND (mFTQ). All the tests were two-tailed and the limit for statistical significance was set at $\mathrm{p}=0.05$. All calculations were carried out using SPSS for Windows, version 18.

\section{RESULTS}

\section{Smoking, comorbid psychiatric diagnoses and ND}

The data on family type, the prevalence of regular daily smoking, the level of ND and comorbid psychiatric diagnoses among boys and girls with $\mathrm{CD}$ are presented in Table 1 . A total $85.9 \%$ of the boys and $86.1 \%$ of the girls smoked regularly to the extent of at least one cigarette a day, and $40.4 \%$ of the boys and $41.7 \%$ of the girls reported a high level of ND. The mean ages of the onset of smoking were 11.9 (sd 1.9) and 12.3 years (sd 1.6) for the boys and girls respectively ( $\mathrm{t}$-test $=-1.33$, $\mathrm{df}=145, \mathrm{p}=0.187)$. The most common comorbid psychiatric diagnosis among both the boys (59.6\%) and the girls $(66.7 \%)$ was substance-related disorders. Comorbid affective and anxiety disorders 
were statistically significantly more prevalent among the girls.

\author{
Insert Table 1 about here
}

\title{
Subtypes of CD and ND
}

The mean sum score of ND in relation to $\mathrm{CD}$ subtypes and comorbid psychiatric diagnoses is presented in Table 2. There was no statistically significant difference in mean sum cores of ND between the types of $\mathrm{CD}$ and ages at the onset of $\mathrm{CD}$ in either the boys or the girls. A comorbid substance use disorder was statistically significantly associated with a higher level of ND among both the boys $(\mathrm{p}<0.001)$ and the girls $(\mathrm{p}=0.019)$. The sum score of ND did not differ significantly between those with or without an affective or anxiety disorder in either the boys or the girls.

Insert Table 2 about here

\section{Correlation between CD and ND}

The mean number of lifetime CD symptoms exceeding the k-SADS threshold level was 6.9 (sd 2.8) among the boys and 5.3 (sd 2.2) among the girls $(\mathrm{F}=4.48, \mathrm{df}=169, \mathrm{p}<0.001)$. As seen in Table 3, the total_number of CD symptoms was positively correlated with the level of ND among both the boys (adj. $r=0.310, p=0.002)$ and the girls (adj. $r=0.324, p=0.006)$. Furthermore, the number of CD symptoms correlated with the level of ND among the boys on all subscales except for aggression, whereas the only statistically significant correlation to be found among the girls was on the subscale of deceitfulness or theft

Insert Table 3 about here 


\section{Predictors of ND}

A regression analysis was used to examine the association of symptoms of $\mathrm{CD}$, age, affective disorder, anxiety disorder and substance-related disorder with the sum score of ND (Table 4). The model showed statistically significant results in both the boys $(\mathrm{F}=5.51, \mathrm{p}<0.001)$ and the girls $(\mathrm{F}=4.53, \mathrm{p}=0.001)$. An increased sum score of ND was statistically significantly associated with an increase in symptoms of $\mathrm{CD}(\mathrm{p}=0.040)$ and with the presence of a substance-related disorder $(\mathrm{p}=0.002)$ in the adolescent boys, while it was shown to be associated with an increase in symptoms of $\mathrm{CD}$ in the adolescent girls $(\mathrm{p}=0.010)$.

Insert Table 4 about here 


\section{DISCUSSION}

The main finding to emerge from this work was that an increased number of CD symptoms was associated with an increased level of ND in both the adolescent boys and girls. As far as we know, this is the first report of such an association. This association was related to substance use disorder among the boys, but not to any other psychiatric disorders. In the girls psychiatric disorders did not explain the ND-CD association. Also, the number of CD symptoms in the boys correlated with the level of ND on all the subscales except aggression, whereas the only statistically significant correlation for the girls was found with deceitfulness or theft.

Both the initiation of smoking and continuous smoking have been shown to have a strong genetic heritability of around 50\%, as also has CD [20,21, 22], and a group of candidate genes have been studied in an attempt to explain both phenomena [20, 23, 24]. Dopaminergic and serotonergic systems have been considered on account of their influence on smoking/nicotine dependence and $\mathrm{CD}$, in view of the fact that, among many other things, both of these neurotransmitter systems mediate a wide spectrum of cognitive functions such as problem-solving under stress [25, 26], leading to the hypothesis that dysfunction in these systems can cause aggressive behaviour [26]. There have also been suggestions that serotonergic functioning is related to aggression itself [24, 27] and more specifically to a reactive form of aggression, impulsivity and poor emotional regulation [28]. Furthermore, low physiological arousal and reduced noradrenergic function have been shown to be associated with proactive aggression and antisocial behaviour [29]. The DSM-IV criteria for adolescent $\mathrm{CD}$ do not differentiate the symptoms by subtypes of aggressive behaviour, i.e. reactive or proactive aggression, and thus future studies with direct behavioural observations and/or valid questionnaires examining reactive vs. proactive aggression in relation to adolescent ND are warranted. 
By contrast with the earlier literature, where ND and CD were linked to same genetic background $[23,30]$, ND was not found here to be related to either the subscale of "aggression towards people and animals" or the "solitary CD" or "childhood-onset CD" subtypes, in spite of the fact that these subtypes are known to be related to life-long persistent antisocial behaviour [31], which has a strong biological background [32]. It is interesting, however, that although the correlation between the number of CD symptoms and the level of ND was present in both genders, our results suggest that aggressive CD and ND are not related, at least in adolescence (before 18 years). On the contrary, ND was related to non-aggressive CD-symptoms of a kind that are often manifested in adolescent peer groups and constitute an only mildly aberrant form of behaviour characteristic of a certain stage in adolescent development. It is possible that heavy smoking and ND among adolescents with CD may be related to familiar factors and peer influences rather than being explained by any single shared genetic factor. A high level of novelty seeking and low avoidance of harm are temperament features that are commonly found to lead to the violation of rules and other disruptive activities in adolescents with CD [33]. This type of behaviour often takes place in peer groups, where both the initiation and continuation of smoking are also more likely to be reinforced. It is also possible that the genetic factor explaining the connection between CD and ND is not associated with aggressive behaviour but with other symptoms of CD.

The strengths of this study were that all the patients were comprehensively interviewed and that the data were gathered using established semi-structured interview techniques $[13,16]$. The series consisted of all the psychiatric adolescent patients hospitalized in a large geographical area in northern Finland within a specific space of time and enabled the formation of a reasonably large sample of adolescents with severe conduct disorder and nicotine dependence.

The limitations of our study include the fact that we were unable to study any genetic determinants 
of smoking, nor did we have any laboratory tests available to verify the presence of ND. Similarly, no information on parental smoking or other parental substance abuse was available. Furthermore, some authors have criticized the DSM-IV classification of CD symptoms into subscales as being artificial and lacking in empirical justification [2, 34]. It may be difficult to generalize the conclusions drawn here to other settings, due to the fact that the series is a selected sample of adolescents with CD symptoms severe enough to lead to psychiatric hospitalization. Finally, inter-rater agreement was not assessed during the initial data collection phase, because the repeated interviews or videotaping were considered to be too heavy a burden on young adolescents with severe psychiatric symptoms.

In summary, in this study the increased number of CD symptoms was associated with the higher level of ND among underage adolescents. This is as far as we know the first study in which the CD symptom subscales in adolescents have been assessed in relation to the degree of ND. Interestingly, ND was related neither to aggressive features of $\mathrm{CD}$ nor to "solitary" or early onset types of $\mathrm{CD}$. We recommend that other substance use habits among adolescents in addition to ND should be investigated in future studies, since comorbid substance use disorders formed a significant covariate in the present analysis. Also of interest in the future would be studies of the genetic relationship between $\mathrm{CD}$ and ND - and also the relationship between environmental factors, non-aggressive CD symptoms and the development of ND among adolescents with CD.

\section{Acknowledgements}

This work received support from the Päivikki and Sakari Sohlberg Foundation, the Ethel F. Donaghue Women's Health Investigator Program at Yale, the Alcoholic Beverage Medical Research Foundation (ABMRF), VA MIRECC and the Jalmari and Rauha Ahokas Foundation.

We thank the staff of adolescent unit 70 at Oulu University Hospital for collecting the data, and all the adolescents involved for their participation. 


\section{The STUDY-70 workgroup:}

Medical supervisors: Professor Pirkko Räsänen, University of Oulu, Department of Psychiatry; Professor Jaakko Lappalainen, Yale University, School of Medicine, Department of Psychiatry; Professor Mauri Marttunen, Helsinki University, Department of Psychiatry. Administrative supervisors: Kaisa Riala, $\mathrm{MD}, \mathrm{PhD}$, Taru Ollinen, $\mathrm{MD}, \mathrm{PhD}$, and Kristian Läksy, MD, PhD, Oulu University Hospital, Department of Psychiatry. Statistical consultants: Helinä Hakko, PhD, and Kaisa Karvonen, B.Sc, Oulu University Hospital, Department of Psychiatry. Senior researcher: Professor Markku Timonen, University of Oulu, Department of Public Health Sciences and General Practice. Researchers: Essi Ilomäki, MD, Risto Ilomäki, MD, Anu-Helmi Luukkonen, B.Med, University of Oulu, Department of Psychiatry; Matti Laukkanen, M.Sc, Oulu University Hospital, Department of Psychiatry.

\section{Financial Disclosures:}

The authors have no conflict of interest, financial or otherwise, related directly or indirectly to the submitted work. 


\section{REFERENCES}

1. DSM-IV-TR (2000). Diagnostic and Statistical Manual of Mental Disorders. Fourth Edition. American Psychiatric Association, Washington, DC.

2. Nock MK, Kazdin AE, Hiripi E, Kessler RC (2006) Prevalence. Subtypes, and Correlates of DSM-IV Conduct Disorder in the National Comorbidity Survey Replication. Psychol Med 36(5): $699-710$

3. Costello EJ, Erkanli A, Federman E, Angold A (1999) Development of psychiatric comorbidity with substance abuse in adolescents: Effects of timing and sex. J Clin Child Psychol 28(3): 298-311

4. Burke JD, Loeber R, Lahey BB (2001) Which aspects of ADHD are associated with tobacco use in early adolescence. J Child Psychol Psychiat 42(4):493-502

5. Rohde P, Kahler CW, Lewinsohn PM, Brown RA (2004) Psychiatric disorders, familiar factors and cigarette smoking: II. Associations with progression to daily smoking. Nicotine Tob Res 6(1):119-132

6. Bagot KS, Berarducci JM, Franken FH, Frazier MJ, Ernst M, Moolchan ET (2001) Adolescents with conduct disorder: early smoking and treatment requests. Am J Addict 16(1): 6266

7. Galéra C, Fombonne E, Chastang J-F, Bouvard M (2005) Childhood hyperactivity-inattention symptoms and smoking in adolescence. Drug Alcohol Depend 78(1):101-108

8. Cornelius JR, Lynch K, Martin CS, Cornelius MD, Clark DB (2001) Clinical correlates of heavy tobacco use among adolescents. Addict Behav 26(2): 273-277

9. Hakko H, Lintunen J, Lappalainen J, Mäkikyrö T, Räsänen P, Timonen M (2006) Nicotine use and dependence and their association to psychiatric disorders in a large sample of adolescent 
psychiatric inpatients. Addict Behav 31(10):1873-1880

10. Elkins IJ, McGue M, Iacono WG (2007) Prospective effects of attentiondeficit/hyperactivity disorder, conduct disorder, and sex on adolescent substance use and abuse. Arch Gen Psychiatry 64(10):1145-1152

11. Prokhorov AV, Pallonen UE, Fava JL Ding L, Niaura R (1996) Measuring nicotine dependence among high-risk adolescent smokers. Addict Behav 21(1):117-127

12. Ilomäki R, Riala K, Hakko H, Lappalainen J, Ollinen T, Räsänen P, Timonen M (2008) Temporal association of onset of daily smoking with adolescent substance use and psychiatric morbidity. Eur Psychiatry 23(2):85-91

13. Kaufman J, Birmaher B, Brent D, Rao U, Flynn C, Moreci P, Williamson D, Ryan N (1997) Schedule for Affective Disorders and Schizophrenia for School-Age Children- Present and Lifetime Version (K-SADS-PL): initial reliability and validity data. J Am Acad Child Adolesc Psychiatry 36(7):980-988

14. Ambrosini PJ (2000) Historical development and present status of the Schedule for Affective Disorders and Schizophrenia for School-Age Children (K-SADS). J Am Acad Child Adolesc Psychiatry 39(1):49-58

15. Kim YS, Cheon KA, Kim BN, Chang SA, Yoo HJ, Kim JW, Cho SC, Seo DH, Bae MO, So YK, Noh JS, Koh YJ, Mc Burnett K, Leventhal B (2004) The reliability and validity of KiddieSchedule for Affective Disorders and Schizophrenia - Present and Lifetime Version - Korean Version (K-SADS-PL-K). Yonsei Med J 45(1):81-89

16. Prokhorov AV, De Moor C, Pallonen UE Hudmon KS, Koehly L, Hu S (2000) Validation of the modified Fagerström tolerance questionnaire with salivary cotinine among adolescents. Addictive Behav 25(3):429-433

17. Chen X, Zheng H, Steve S, Gong J, Stacy A, Xia J, Gallaher P, Dent C, Azen S, Shan J, Unger JB, Johnson CA (2002) Use of Fagerström Tolerance Questionnaire for measuring nicotine 
dependence among adolescent smokers in China: a pilot test. Psychol Addict Behav 16(3):260-263

18. Isohanni M, Moilanen I, Rantakallio P (1991) Determinants of teenage smoking, with special reference to non-standard family background. Br J Addict 86(4):391-398

19. Loeber R, Hay D (1997) Key issues in the development of aggression and violence from childhood to early adulthood. Annu Rev Psychol 48:371-410

20. Li MD (2003). The genetics of smoking related behavior: a brief report. Am J Med Sci 326(4):168-173

21. Gelhorn HL, Stallings MC, Young SE, Corley RP, Rhee SH, Hewitt JK (2005) Genetic and environmental influences on conduct disorder: symptom, domain and full-scale analyses. J Child Psychol Psychiatry 46(6): 580-591

22. Button TM, Rhee SH, Hewitt JK, Young SE, Corley RP, Stallings MC (2007) The role on conduct disorder in explaining the comorbidity between alcohol and illicit drug dependence in adolecence. Drug Alcohol Depend 87(1):46-53

23. Malmberg K, Wargelius HL, Lichtenstein P, Oreland L, Larsson JO (2008) ADHD and disruptive behavior scores - associations with MAO-A and 5-HTT genes and with platelet MAO-B activity in adolescents. BMC Psychiatry 8:28

24. Sakai JT, Young SE, Stallings MC et al (2006). Case-control and within-family test for an association between conduct disorder and 5HTTLPR. Am J Med Genet B Neuropsychiatr Genet 141B(8):825-832

25. Luciana M, Collins PF, Depue RA (1998) Opposing roles for dopamine and serotonin in the modulation of human spatial working memory functions. Cereb Cortex 8(3):218-126

26. Lucki I (1998) The spectrum of behaviors influenced by serotonin. Biol Psychiatry 44(3):151-162

27. Moffitt TE, Brammer GI, Caspi A, Fawcett JP, Raleigh M, Yuwiler A, Silva P (1998) Whole blood serotonin relates to violence in a epidemiological study. Biol Psychiatry 43(6): 446- 
28. Gerra G, Garofano L, Zaimovic A, Moi G, Branchi B, Bussandri M, Brambilla F, Donnini C (2005) Association of the serotonin transporter promoter polymorphism with smoking behaviour among adolescents. Am J Med Genet B Neuropsychiatr Genet 135B(1):73-78

29. Krakowski M (2003) Violence and serotonin: influence of impulse control, affect regulation, and social functioning. J Neuropsychiatry Clin Neurosci. 15(3):294-305

30. Raine A (2002) Annotation: The role of the prefrontal deficits, low autonomic arousal, and early health factors in the development of antisocial and aggressive behavior in children. J Child Psychol Psychiatry 43(4): 417-434

31. Söderström H, Sjödin AK, Carlstedt A, Forsman A (2004) Adult psychopathic personality with childhood-onset hyperactivity and conduct disorder: a central problem constellation in forensic psychiatry. Psychiatry Res 121(3):271-280

32. Ferguson CJ (2010) Genetic contributions to antisocial personality and behavior: a metaanalytic review from an evolutionary perspective. J Soc Psychol 150(2):160-180

33. Schmeck K, Poustka F (2001) Temperament and disruptive behavior disorders. Psychopathology 34(3):159-163

34. Janson H, Kjelsberg E (2006) Factor structure and individual patterns of DSM-IV conduct disorder criteria in adolescent psychiatric inpatients. Nord J Psychiatry 60(2):168- 175

Table 1. Family type, smoking status, level of nicotine dependence and comorbid psychiatric diagnoses among boys and girls with conduct disorder.

\begin{tabular}{llll}
\hline Boys & Girls & $\begin{array}{l}\text { Gender } \\
\text { difference }\end{array}$ \\
$(n=99)$ & $(n=72)$ & p-value* \\
& $n(\%)$ & $n(\%)$ & \\
\hline
\end{tabular}


Family type

Two biological parents

One biological parent

Child welfare placement

Other

Regular smoking ( $\geq 1 \mathrm{cig} / \mathrm{day}$ )

Nicotine dependence

No ND/Non-smoker

Moderate ND

High ND

Comorbid psychiatric diagnoses

$$
20(20.2)
$$

$17(23.6)$

0.257

$27(27.3)$

$21(29.2)$

$43(43.4)$

$22(30.6)$

$9(9.1)$

$12(16.7)$

85 (85.9)

$62(86.1)$

0.963
$20(20.2)$
$12(16.7)$
0.840
$39(39.4) \quad 30(41.7)$
$40(40.4) \quad 30(41.7)$

$\begin{array}{llll}\text { Affective disorder } & 30(30.3) & 35(48.6) & 0.015 \\ \text { Anxiety disorder } & 11(11.1) & 21(29.2) & 0.003 \\ \text { Substance related disorder } & 59(59.6) & 48(66.7) & 0.346\end{array}$

Note: frequencies indicate positive response if not otherwise specified

* Pearson's Chi-square Test or Fisher's Exact Test, two-tailed significance.

Table 2. Difference of mean sum score of the modified Fagerström Tolerance Questionnaire for nicotine dependence among adolescents in relation to type of conduct disorder and comorbid psychiatric diagnoses. 


\begin{tabular}{|c|c|c|c|c|}
\hline & \multicolumn{4}{|c|}{ Sum score of $\mathrm{mFTQ}$} \\
\hline & \multicolumn{2}{|c|}{ Adolescent boys } & \multicolumn{2}{|c|}{ Adolescent girls } \\
\hline & mean (sd) & p-value* & mean (sd) & p-value* \\
\hline & & & GIRLS & \\
\hline Type of CD & & 0.120 & & 0.724 \\
\hline Group type & $4.4(2.3)$ & & $4.8(2.3)$ & \\
\hline Solitary aggressive type & $3.9(2.7)$ & & $4.6(2.3)$ & \\
\hline Undifferentiated type & $5.3(2.3)$ & & $5.2(1.9)$ & \\
\hline Type of CD onset & & 0.807 & & 0.935 \\
\hline Childhood-onset type & $4.4(2.5)$ & & $4.7(2.2)$ & \\
\hline Adolescent-onset type & $4.5(2.3)$ & & $4.7(2.3)$ & \\
\hline \multicolumn{5}{|l|}{ Comorbid psychiatric diagnoses } \\
\hline Affective disorder & & 0.371 & & 0.101 \\
\hline Yes & $4.2(2.3)$ & & $5.3(1.9)$ & \\
\hline No & $4.7(2.5)$ & & $4.4(2.5)$ & \\
\hline Anxiety disorder & & 0.343 & & 0.209 \\
\hline Yes & $3.9(2.8)$ & & $5.3(2.2)$ & \\
\hline No & $4.6(2.4)$ & & $4.6(2.2)$ & \\
\hline Substance related disorder & & $<0.001$ & & 0.019 \\
\hline Yes & $5.4(1.9)$ & & $5.3(2.4)$ & \\
\hline No & $3.3(2.5)$ & & $4.0(2.0)$ & \\
\hline
\end{tabular}

Note: $\mathrm{mFTQ}=$ the modified Fagerström Tolerance Questionnaire for nicotine dependence among adolescents [11] 
* Student's t-test or Analysis of Variance (ANOVA) test, two-tailed significance.

Table 3. Correlation between the number of symptoms on each Conduct Disorder subscale and the sum score on the Fagerström Tolerance Questionnaire ( $\mathrm{mFTQ}$ ) .

\begin{tabular}{lllll}
\hline Number of symptoms & $r$ & $p$-value & adj $r$ & $p$-value \\
\hline & & & & \\
BOYS & & & & \\
Total number of symptoms & 0.358 & $<0.001$ & 0.310 & 0.002 \\
Aggression & 0.140 & 0.167 & 0.067 & 0.514 \\
Destruction of property & 0.231 & 0.022 & 0.224 & 0.026 \\
Deceitfulness or theft & 0.256 & 0.011 & 0.214 & 0.035 \\
$\quad$ Serious violations or rules & 0.297 & 0.003 & 0.334 & 0.001
\end{tabular}

GIRLS

Total number of symptoms

$\begin{array}{llll}0.406 & <0.001 & 0.324 & 0.006\end{array}$

Aggression

0.169

0.156

0.143

0.235

Destruction of property

0.097

0.419

0.037

0.760

Deceitfulness or theft

$0.362 \quad 0.002$

0.328

0.005

Serious violations or rules

$\begin{array}{lll}0.244 & 0.039 & 0.191\end{array}$

0.110

adj $r$ = partial correlation, age-adjusted

Table 4. Predictors for ND among male and female adolescents. 


$\begin{array}{llll}\text { ADOLESCENT BOYS } & \beta & \mathrm{t} & \mathrm{p} \text {-value } \\ & & & \\ \text { Symptoms of CD } & 0.22 & 2.09 & 0.040 \\ \text { Age at admission } & -0.05 & -0.43 & 0.672 \\ \text { Affective disorder } & -0.09 & -0.96 & 0.337 \\ \text { Anxiety disorder } & 0.03 & 0.32 & 0.748 \\ \text { Substance related disorder } & 0.35 & 3.23 & 0.002\end{array}$

\section{ADOLESCENT GIRLS}

$\begin{array}{lccc}\text { Symptoms of CD } & 0.30 & 2.66 & 0.010 \\ \text { Age at admission } & 0.17 & 1.41 & 0.163 \\ \text { Affective disorder } & 0.14 & 1.27 & 0.208 \\ \text { Anxiety disorder } & 0.01 & 0.06 & 0.955 \\ \text { Substance related disorder } & 0.18 & 1.59 & 0.117\end{array}$

Note: Regression analysis, dependent variable was the Fageströn sum score for nicotine dependence. 